\title{
Evaluation of gas fuel and biofuel usage in turbine
}

\author{
Dalya H. Al-Mamoori ${ }^{1}$, Mohanad H. Aljanabi ${ }^{2}$, Omar Muhammed Neda ${ }^{3}$, Zaid H. Al-Tameemi ${ }^{4}$, \\ Ali Assim Alobaidi ${ }^{5}$ \\ 1,2,4 Departement of Electrical Power Engineering, Al-Furat Al-Awsat Technical University, Najaf, Iraq \\ ${ }^{3}$ Depertmant of Engineering Affairs, Sunni Diwan Endowment, Bagdad, Iraq \\ ${ }^{5}$ Depertmant of Engineering, Babylon Technical Institute, Al-Furat Al-Awsat Technical University, Najaf, Iraq
}

\begin{tabular}{l} 
Article Info \\
\hline Article history: \\
Received Dec 6, 2018 \\
Revised Jan 21, 2019 \\
Accepted Feb 3, 2019 \\
\hline
\end{tabular}

\section{Keywords:}

Biofuel

Gas turbine (GT_Se)

MATLAB

Micro-gas turbine

Renewable energy

\begin{abstract}
Modern gas turbines are a significant source for power generation and prime mover for marine propulsion. The depleting fossil fuel sources have provided a cue for broader implementation and usage of renewable energy. Biofuel has been touted as a substitute for natural gas to power gas turbines. To confirm the dependability and reliability of this attempt in a complex multi-domain system, for example, the gas turbine, the fuel system of the micro-gas turbine is designed and modelled using MATLAB Simulink. The model simulates the transient and steady state of a gas turbine's nominal functional situations. Evaluations between the field data and simulation outcomes validate a high degree of correspondence. The fuel system in the micro-gas turbine simulation model is also optimized with the experimental data.
\end{abstract}

Copyright (C) 2019 Institute of Advanced Engineering and Science. All rights reserved.

\section{Corresponding Author:}

Dalya H. Al-Mamoori,

Departement of Electrical Power Engineering,

Al-Furat Al-Awsat Technical University,

Najaf, Iraq, Tel: 009647718313501.

Email: daliahamza784@gmail.com

\section{INTRODUCTION}

On the global context, the oil crisis, the growing demand of electricity, which has caused many technical issues for the power systems, and tighter control on the greenhouse gas emission have forced industry experts and researchers to think of numerous alternative energy resources.During the Climate Change Conference in Copenhagen in 2009s, the subjects discussed were carbon capture, and storage, biofuels, adaptation financing, emission targets. The ever-rising cost for fossil fuels is another major driver for considering alternative fuels in gas turbines. The International Energy Agency has reported that energy needs will rise about $1.6 \%$ per year from 2006-2030s .with increasing demand of gas power and renewable energy resources as shown in Figure 1 [1]-[5]. The need to ecofriendly fuel becomes essential worldwide task when global calefactory and airport air quality problems are to be diminished [6]-[8]. the efficiency improvement of gas turbine units lead to decrease emissions, therefore the Biofuel is in the process of being put into usage.The operational flexibility of these systems is one of the leading problems for the industry [1]. The results of the Gas turbine (GT_Se) can be used to estimate pollutant emissions and carbon reductions by biodiesel in power generation industry [9]. the preliminary surveys were conducted on turbine related burners under atmospheric pressure and temperature transducers along with high-speed predicting techniques can provide a better understanding [10]. 


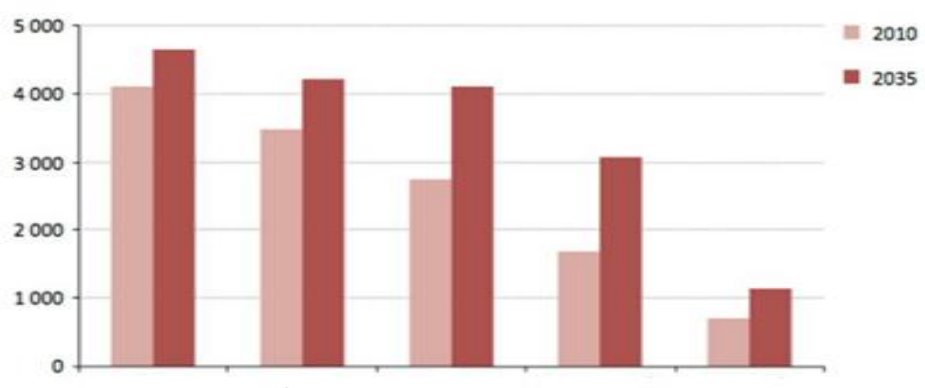

Figure 1. The world energy demand of fuel [11]

\section{NUMERICAL MODEL}

An accurate gas turbine model integrated with experimental data from the Capstone C30 microturbine, which is located at Lab, is designed and simulated in MATLAB Simulink [12]. The gas turbine model developed, named "GT_Se" will be simulated and run on gas fuel and biofuel settings, with all the important parameters and characteristics recorded and analysed. "GT_Se" represents a real industrial gas turbine with built-in control loops, turbine components and various operating dynamics. The fuel valve positioner settings, i.e. $a, b$ and $c$ (for biofuel) and $d, e$ and $f$ (for gas fuel) will be optimised using MATLAB Simulink's Optimizer block [13]. The fuel valve positioner settings will determine the type of fuel gas characteristics in the "GT_Se". The data obtained from "GT_Se" gas turbine model is then validated with real experimental data from the Capstone C30 [14]. Neat vegetable oils are not appropriate as gas turbine fuels; they must be improved to bring their combustion-associated properties nearer to those of diesel oil [13]. This fuel variation is chiefly aimed at decreasing the viscosity to mitigate flow associated problems Panchasara et al. [15] indicated that the viscosity of mineral diesel is lower than biodiesel by $45 \%$ to $55 \%$. The higher fuel viscosity of biodiesel could affect the outcome in poor atomization and may clog the fuel nozzles.. Esterification is one of the proven methods is the same active technique to adjust the vegetable oil structure and decrease its viscosity [16]. Tan and Palanisamy [17] in their work conducted numerous performance tests to study the combustion distinguishing of biodiesel resulting from Waste Cooking Oil (WCO) chiefly from palm oil resource in a 30-kilowatt microturbine. BD20, i.e. biodiesel blend of 20\% (a mixture of $20 \%$ WCO and $80 \%$ diesel) reached the maximum efficiency as compared with other blending ratios. Thus, the biofuel discussed from this point onwards is based on the biodiesel of the BD20.

\section{RESULTS AND ANALYSIS}

The industrial gas turbine constructed from compressor, the combustion chamber and the turbine sector [18]. "GT_Se" has its fundamental design constructed on the Rowen's model [18] and incorporate D. N. Gaonkar's microturbine model as shown in Figure 2 [19].

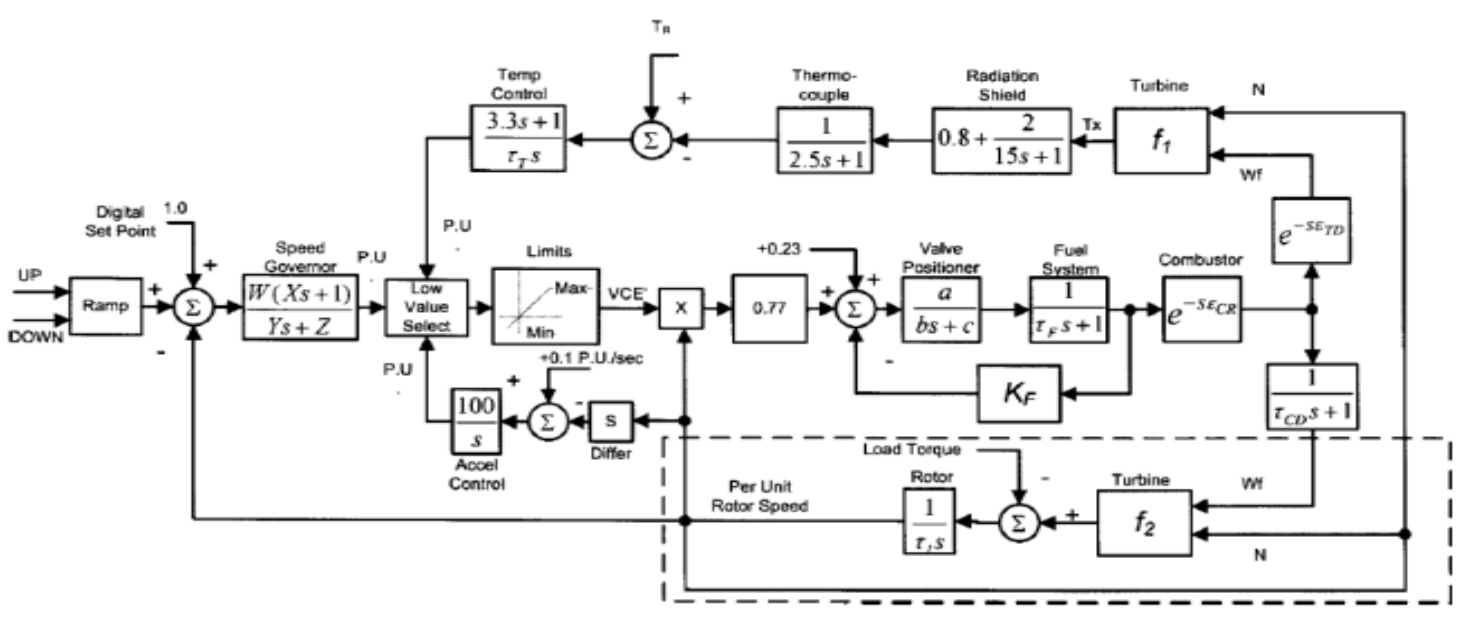

Figure 2. Rowen's gas turbine model [18]

Indonesian J Elec Eng \& Comp Sci, Vol. 14, No. 3, June 2019 : 1097 - 1104 
The Rowen's model has been widely referred to and used to study the effects of the governor on gas turbine systems. The Capstone C30 is liquid fuel and gas fuel capable, and laboratory tests were done on both gas fuel and biofuel. Experimental data obtained include the turbine exhaust temperature, pressure, turbine speed, torque, and power. These data will be used to optimise "GT_Se" valve positioner settings, and to validate the accuracy of "GT Se" gas turbine model. Centeno in [20] offers a more comprehensive interpreting and the importance of the various control; loops as shown in Figure 3. "GT_Se" is modelled and simulated in MATLAB Simulink and can provide power output information and parameters such as turbine speed, exhaust temperature, load torque, fuel flow, and fuel control signals. It is developed to know how to represent the steady-state conditions and transient behaviours of a typical gas turbine operation.

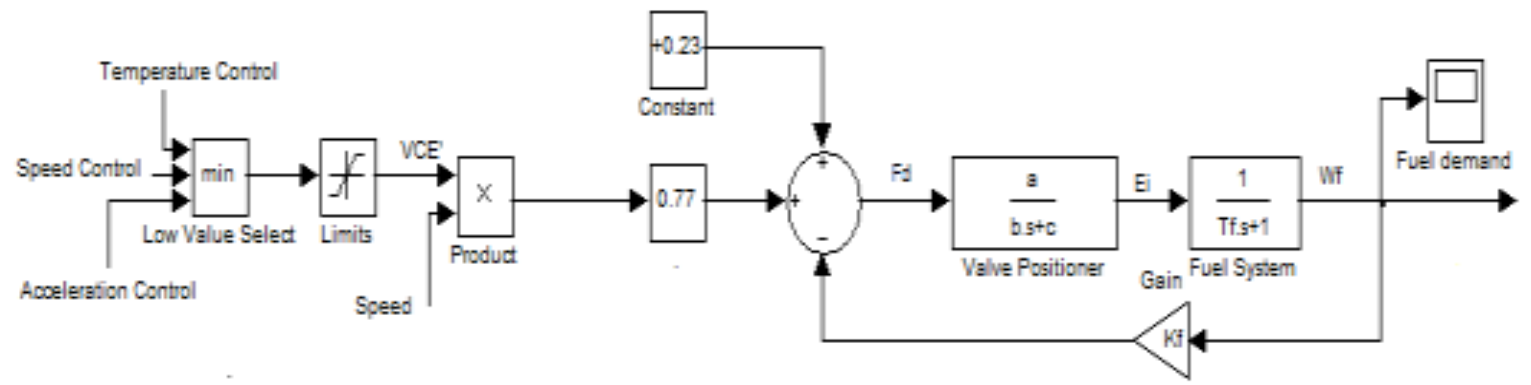

Figure 3. Fuel control block diagrams in "GT_Se."

The fuel gas control scheme in Figure 4 is consisted two valves, the first in the series is the valve positioner, which controls the pressure between the two valves as a function of speed. While the second valve has a linear area against lift characteristics and to attain fuel flow velocity. If the valve position is continued related to the Vce signal, the remaining result is a flow rate of fuel is relative to the multiplication product of Vce and turbine speed [21].

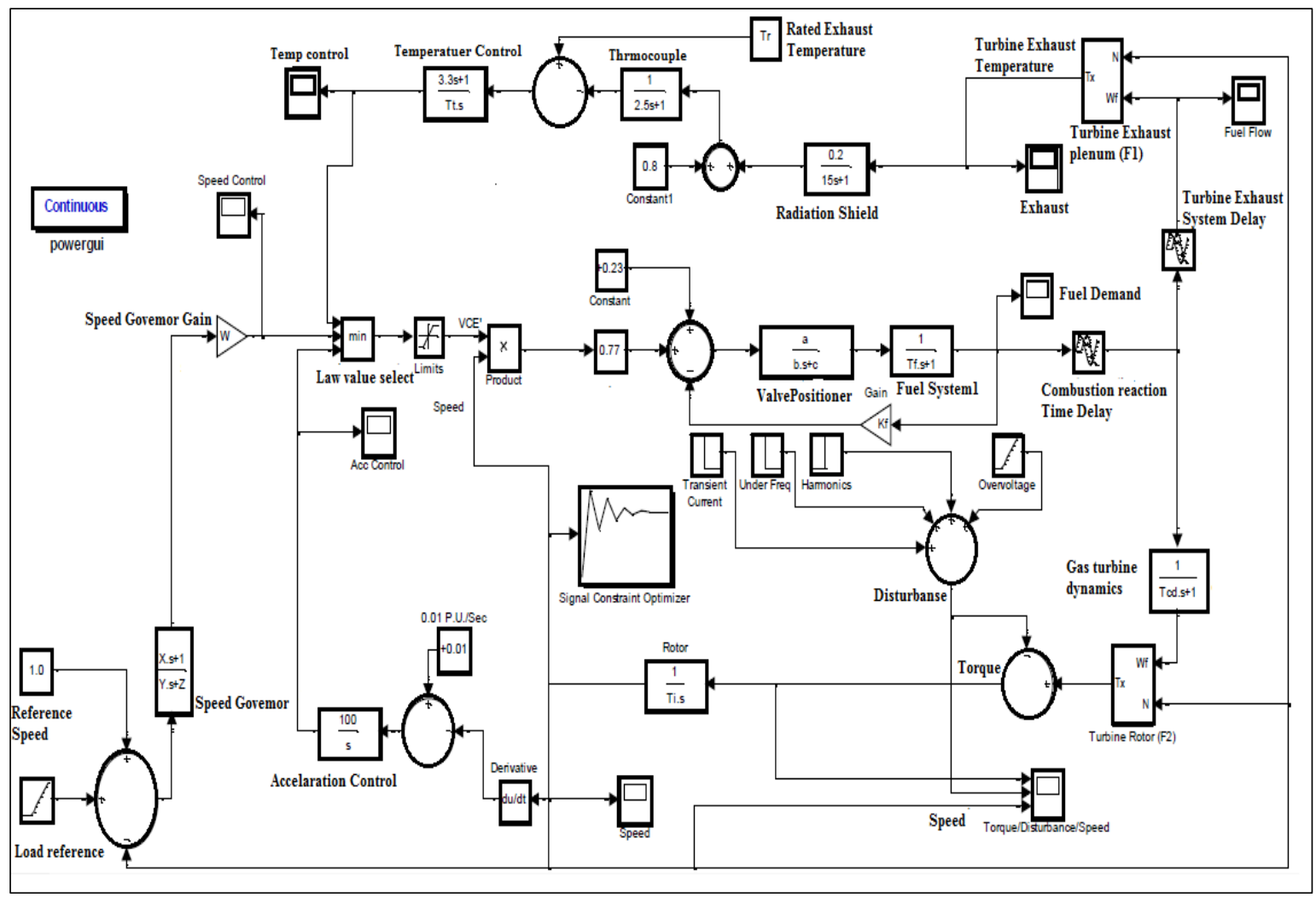

Figure 4. "GT_Se" gas turbine model in MATLAB Simulink 
The fuel demand signals from speed, temperature and acceleration control are consider as the input request signals to the fuel control. Whereas the output signal is the fuel flow WF that will flow into the gas turbine system [22]. The valve positioner transfer function is:

$$
E i=\frac{a}{b . s+c} \cdot F d
$$

moreover, the fuel scheme actuator transfer function is:

$$
\mathrm{Wf}=\frac{1}{\mathrm{Tf} \cdot \mathrm{s}+1} \cdot \mathrm{Ei}
$$

The valve positioner settings for biofuel $(a, b$ and $c$ ) and gas fuel $(d, e$ and $f)$ are optimised by using the "signal constraint optimiser" block in MATLAB Simulink. Simplex method was implemented to compute and optimise the valve positioner values as shown in Figure 5.

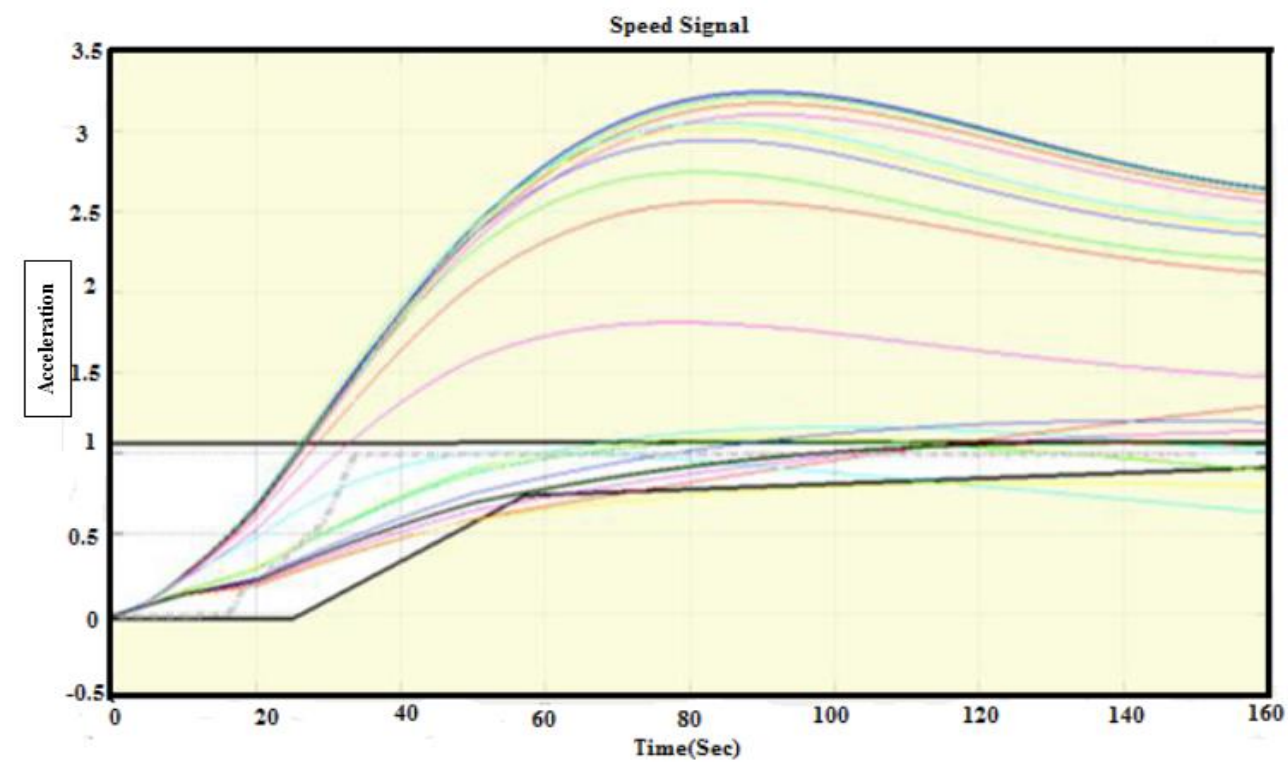

Figure 5. Optimisation of valve positioner settings

Table 1. Value Positional Setting for Biofuel and Gas Fuel

\begin{tabular}{cc}
\hline Notation & Value \\
\hline A & 0.1788 \\
B & 0.0354 \\
C & 0.2254 \\
D & 0.1199 \\
E & 0.8419 \\
F & 0.0859 \\
\hline
\end{tabular}

A more accurate micro-gas turbine simulation model is completed by incorporating values from Table1 into "GT_Se". Further studies and research can be done in terms of the response and dynamics of the micro-gas turbine operating on both gas fuel and biofuel. The first test is to operate the micro-gas turbine model "GT_Se" on biofuel and gas fuel parameters, without introducing any load torque disturbance. As discussed earlier, the primary fuel of micro-gas turbine is natural gas, which is considered the optimum fuel for the micro-gas turbine.

Figure 6 demonstrate the micro-gas turbine fuel flow when running of fuel gas and biofuel. Figure 7 shows the difference in turbine speed during gas firing and biofuel firing. While Figure 8 shows the torque generated on the turbine rotor. 


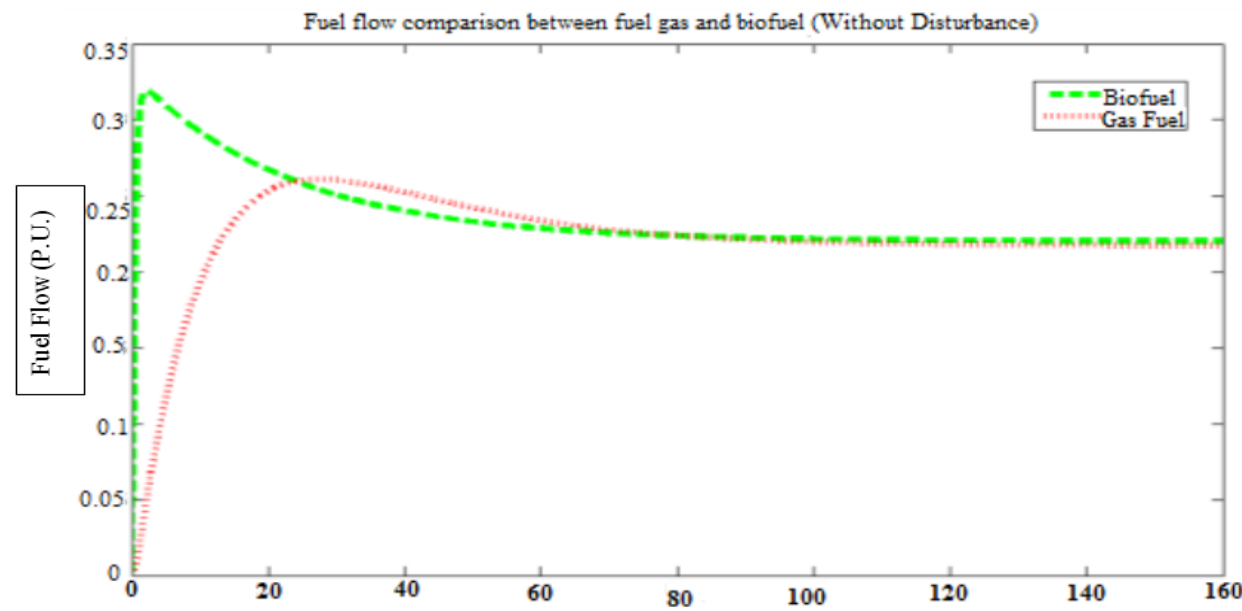

Figure 6. Fuel flow comparison between fuel gas and biofuel (without disturbance)

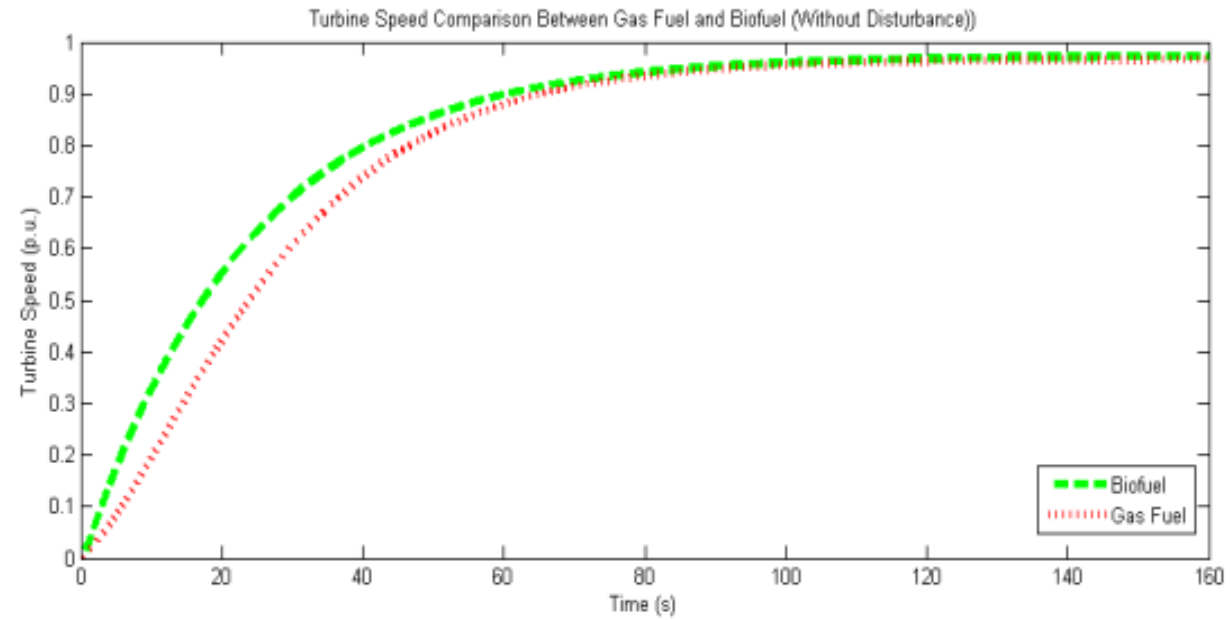

Figure 7. Turbine comparison between fuel gas and biofuel (Without Disturbance)

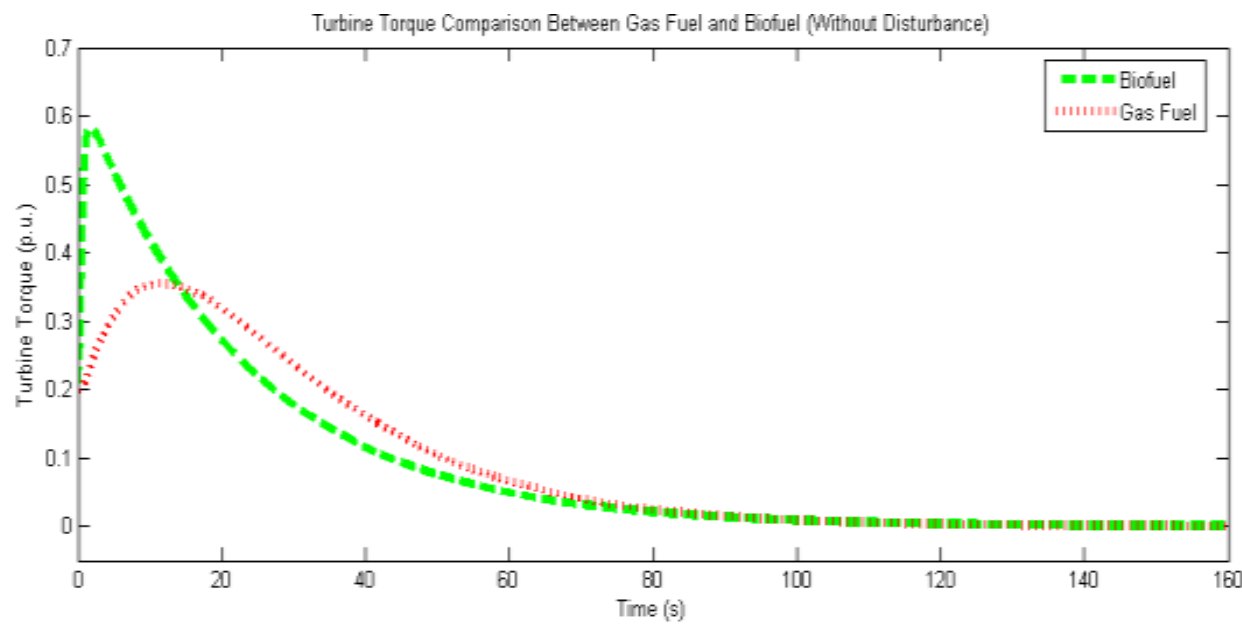

Figure 8. Turbine torque comparison between gas fuel and biofuel (without disturbance) 
A load torque disturbance is introduced to "GT_Se" to test and study the dynamics of the micro-gas turbine, as shown in Figures 9 and 10.

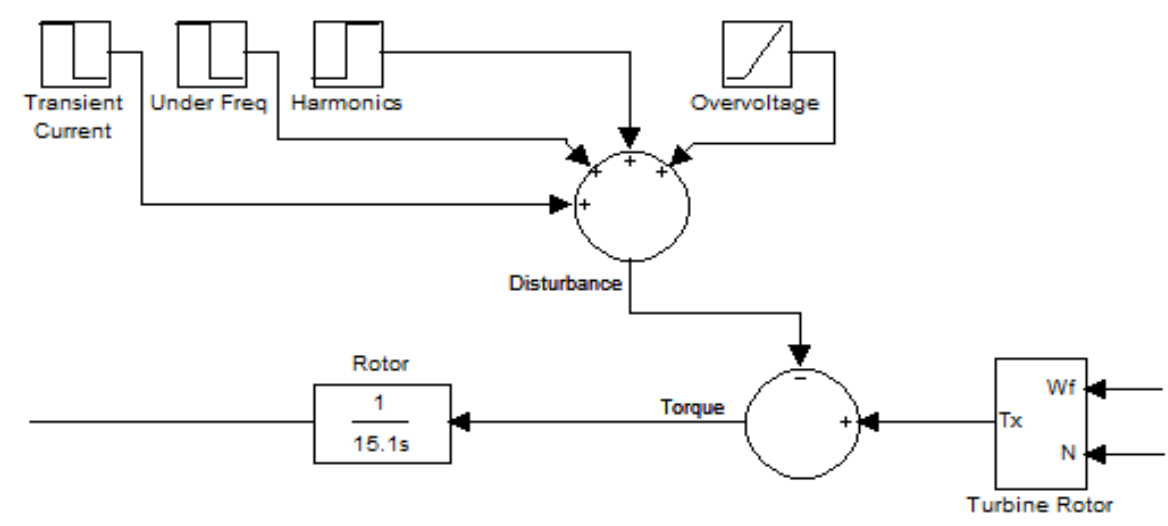

Figure 9. Load torque disturbance in "GT_Se"

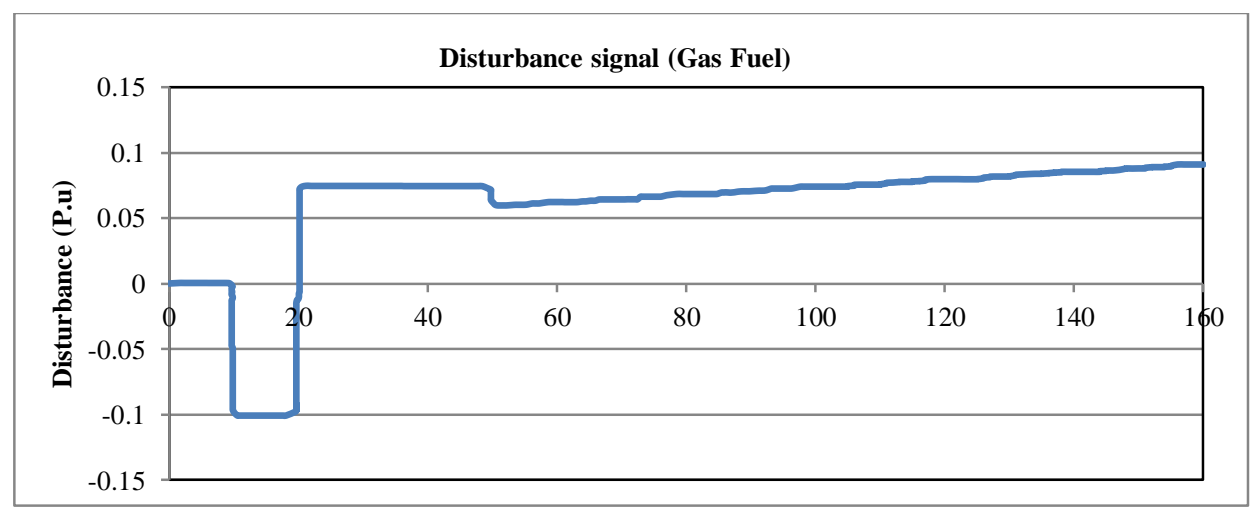

Figure 10. Disturbance signal

Figure 11 shows the fuel flow into the gas turbine during the disturbance. The gas turbine controller is capable of controlling and maintaining a constant and steady fuel flow, which is vital to prevent flame off (air-fuel mixture is too lean) or over-temperature (air-fuel mixture is too costly) [23]. These situations will trip the turbine and cause severe damages.

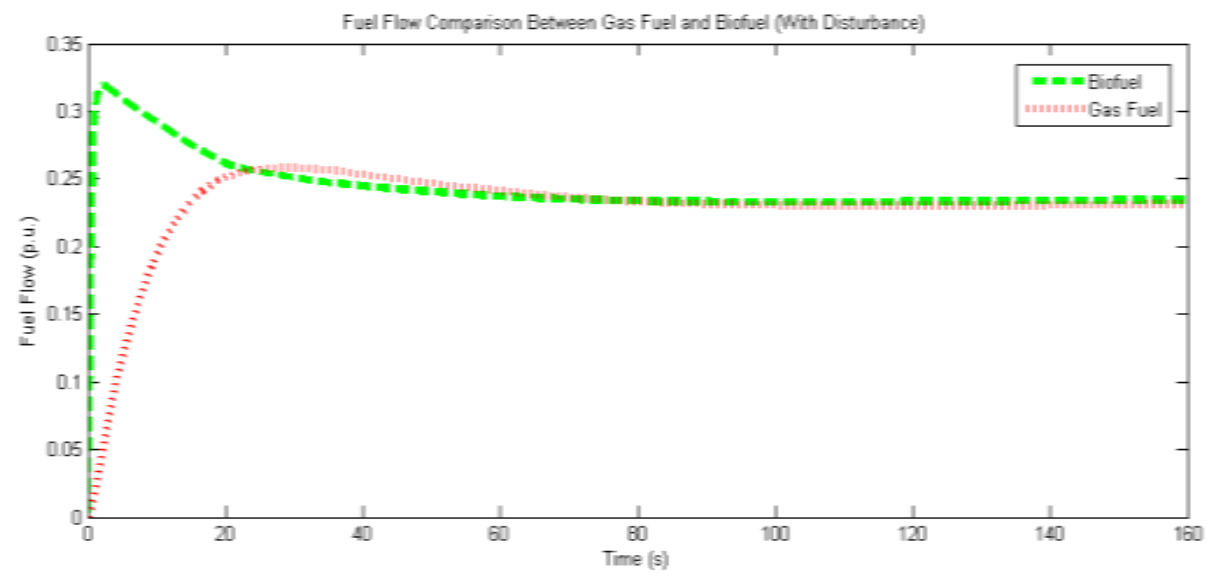

Figure 11. Fuel flow comparison between gas fuel and biofuel (with disturbance) 
Figure 12 represents the turbine speed during gas turbine startup sequence under load torque disturbance. Both controllers for gas fuel and biofuel respectively were capable of maintaining the turbine speed at more than 0.8 p.u. in the presence of the load torque disturbance.

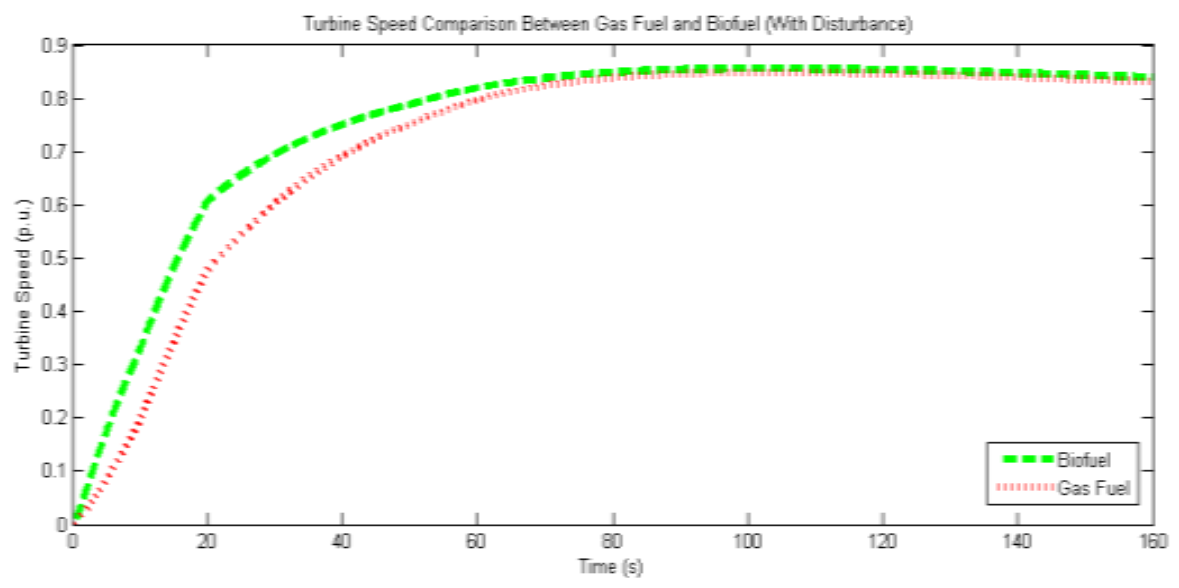

Figure 12. Turbine speed comparison between gas fuel and biofuel (with disturbance)

Figure 13 shows the variation of turbine torque during load torque disturbance. A sharp drop of torque is observed at the 20 s due to the sudden surge of torque disturbance. However, both micro-gas turbine fuel models can adapt and contain the fault. Overall, "GT_Se" micro-gas turbine simulation model showed that the performance of biofuel is comparable that of natural gas. A disturbance signal was introduced to study the response, and all simulation results imply that biofuel can be theoretically used as an alternative fuel.

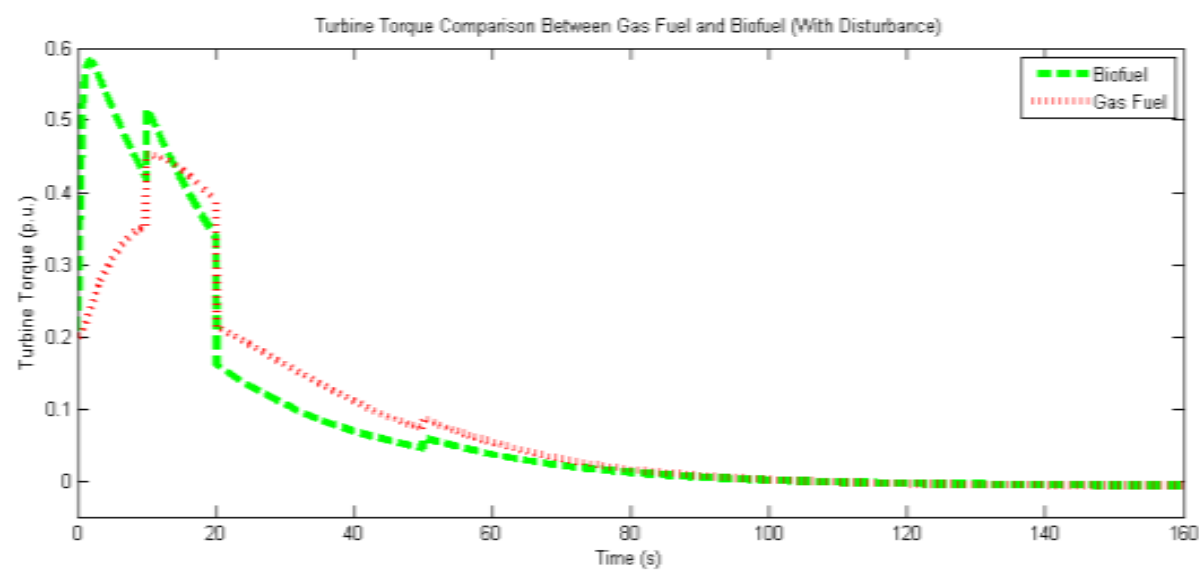

Figure 13. Turbine torque comparison between gas fuel and biofuel (with disturbance)

\section{CONCLUSIONS}

Evaluation and data validation showed "GT_Se" is practically accurate and suitable for dynamic studies. By optimising and incorporating gas fuel and biofuel valve settings, "GT_Se" reflects actual turbine operation and provides an insight into the performance and response of a real industrial gas turbine. The results and performance of biofuel in "GT_Se" illustrated desired dynamic response and fuel consumption characteristics. To further prove the feasibility of biofuel usage in a gas turbine, a load torque disturbance was also introduced in "GT_Se" model. "GT_Se" was able to respond to the fault. Additional, the fuel flexibility and diminishing operating cost are a required feature to meet all the characteristics while in gas turbines. 


\section{REFERENCES}

[1] R. K. Bhargava, L. Branchini, F. Melino, and A. Peretto, "Available and Future Gas Turbine Power Augmentation Technologies: Techno-Economic Analysis in Selected Climatic Conditions," J. Eng. Gas Turbines Power, 2012, vol. 134, no. 10, p. 102001.

[2] H. Kurji, Agustin Valera-Medina, Jon Runyon, Anthony Giles, Daniel Pugh, Richard Marsh, N. Cerone, F. Zimbardi, and V. Valerio., "Combustion characteristics of biodiesel saturated with pyrolysis oil for power generation in gas turbines," Renew. Energy, 2016, vol. 99, pp. 443.

[3] Al-Tameemi, Z. H., Enawi, H. H., Al-Anbar, K. M., \& Almukhtar, H. M. (2018). Transient Stability Improvement of the Power Systems. Indonesian Journal of Electrical Engineering and Computer Science, 12(3), 916-923.

[4] Dawoud, S. M., \& Lin, X. (2015). Study of hybrid PV-wind energy system to isolated micro-grid. Indonesian Journal of Electrical Engineering and Computer Science, 16(2), 221-231.

[5] H. Kurji, A. Valera-Medina, Aniekan Okon, C. Cheng-Tung, " Carbon dioxide blends to reduce emissions under premixed combustion mode." In 13th International Conference on Energy for a Clean Environment July 2-6, São Miguel, Azores, Portugal, 2017.

[6] S. Sgouridis, P. A. Bonnefoy, and R. J. Hansman, "Air transportation in a carbon-constrained world: Long-term dynamics of policies and strategies for 136 mitigating the carbon footprint of commercial aviation," Transp. Res. Part A Policy Pract., 2011, vol. 45, no. 10, pp. 1077-1091.

[7] Yu, S., Subash, A. A., Liu, X., Liu, X., Hodzic, E., Szasz, R.Z., Bai, X.S., Li, Z.S., Collin, R., Aldén, M., \& Lörstad, D., "Numerical and Experimental Investigation of the Flame Structures in a New Lab-Scale Gas Turbine Swirl Burner", ASME Turbo Expo 2018.

[8] Khan, M. R. B., Pasupuleti, J., Al-Fattah, J., \& Tahmasebi, M. (2018). Optimal Grid-Connected PV System for a Campus Microgrid. Indonesian Journal of Electrical Engineering and Computer Science, 12(3), 899-906.

[9] Mohamed Alalim Altaher, Gordon E. Andrews and Hu Li, Study of Biodiesel Emissions and Carbon Mitigation in Gas Turbine Combustor, American Journal of Engineering Research (AJER), ISSN: 2320-0847, Volume-03, Issue11, pp-290-298, 2018.

[10] Subash, A. (2018). Laser-Based Investigations of Combustion Phenomena in Gas Turbine Related Burners. Department of Physics, Lund University.

[11] The carbon Brief, "Seven essential graphs from the IEA's World Energy Outlook," 2012. [Online]. Available: http://www.carbonbrief.org/blog/2012/11/favourite-graphs-from-iea.

[12] Simulink: "User's Guide," The MathWorks, Inc., 1998.

[13] Agresti, M., Camporeale, S. M., and Fortunato, B., 2000, “An Object-Oriented Program for the Dynamic Simulation of Gas Turbines," ASME Paper No.2000-GT-42.

[14] Kaltschmitt, M., Reinhardt, G. A., and Stelzer, T., 1997, “Life Cycle Analysis of Biofuels under Different Environmental Aspects," Biomass Bioenergy, 12, pp. 121-134.

[15] Agarwal, A. K., 1999, "Performance evaluation and tribological studies on a biodiesel-fueled compression ignition engine,’ PhD thesis, Center for Energy Studies, Indian Institute of Technology, Delhi, India, p. 344.

[16] Panchasara, H, Simmons, B. M., Agrawal, A. K., Spear, S. K., and Daly, D. T., 2008, "Combustion Performance of Biodiesel and Diesel-Vegetable Oil Blends in a Simulated Gas Turbine Burner," ASME Paper No. GT2008-51496.

[17] Kexin Liu, John P. Wood, "Biodiesel as an Alternative Fuel in Siemens Dry Low Emissions Combustors: Atmospheric and High-Pressure Rig Testing”, ASME Journal of Gas Turbines and Power, September 14, 2009

[18] Ee Sann Tan, Kumaran Palanisamy, "Experimental and Simulation Study of Biodiesel Combustion in a Microturbine", Proceedings of ASME Expo 2008, June 9-13, 2008, Berlin.

[19] W. I. Rowen, "Simplified mathematical representations of single shaft gas turbines in mechanical drive service," presented at the Int. Gas Turbine and Aeroengine Conger. and Expo., Cologne, Germany, 1992.

[20] D. N. Gaonkar, "Modeling and Simulation of Microturbine Based Distribution Generation System," IEEE Trans. On Power System, 2006.

[21] Speedtronic ${ }^{\mathrm{TM}}$ Mark V Gas Turbine Control System, GER-3658D.

[22] P. Centeno, I. Egido, C. Domingo, F. Fernandez, L. Rouco, and M. Gonzalez, "Review of gas turbine models for power system stability studies," presented at the 9th Spanish Portuguese Congress on Electrical Engineering, Marbella, Spain, 2005.

[23] Gas Turbine Liquid Fuel Specification, General Electric (GE Co.), GEI 41047H. 